\title{
Matrix metalloproteinase expression in the olfactory epithelium
}

\section{Citation}

Tsukatani, Toshiaki, Helen L. Fillmore, Heather R. Hamilton, Eric H. Holbrook, and Richard M. Costanzo. 2003. "Matrix Metalloproteinase Expression in the Olfactory Epithelium." NeuroReport 14 (8) (June): 1135-1140. doi:10.1097/00001756-200306110-00007.

\section{Published Version}

10.1097/00001756-200306110-00007

\section{Permanent link}

http://nrs.harvard.edu/urn-3:HUL.InstRepos:32416991

\section{Terms of Use}

This article was downloaded from Harvard University's DASH repository, and is made available under the terms and conditions applicable to Other Posted Material, as set forth at http:// nrs.harvard.edu/urn-3:HUL.InstRepos:dash.current.terms-of-use\#LAA

\section{Share Your Story}

The Harvard community has made this article openly available.

Please share how this access benefits you. Submit a story.

\section{Accessibility}




\title{
Matrix metalloproteinase expression in the olfactory epithelium
}

\author{
Toshiaki Tsukatani ${ }^{1,4}$, Helen L. Fillmore ${ }^{2,3}$, Heather R. Hamilton ${ }^{2}$, Eric H. Holbrook ${ }^{1}$, and \\ Richard M. Costanzo 1',CA \\ ${ }^{1}$ Department of Physiology, PO Box 980551, Virginia Commonwealth University, Medical College \\ of Virginia Campus, Richmond, VA 23298 - 0551 \\ ${ }^{2}$ Department of Surgery, PO Box 980551, Virginia Commonwealth University, Medical College of \\ Virginia Campus, Richmond, VA 23298 - 0551 \\ ${ }^{3}$ Research Service, Hunter Holmes McGuire Department of Veterans Affairs Medical Center, \\ Richmond, VA, USA \\ ${ }^{4}$ Department of Otorhinolaryngology, School of Medicine, Kanazawa University, 13-1 Takaramachi \\ Kanazawa, 920-0934, Japan
}

\begin{abstract}
The olfactory epithelium contains neuronal progenitor cells capable of continuous neurogenesis and is a unique model for studying neural degeneration, regeneration, axon outgrowth and recovery from injury. Matrix metalloproteinases (MMPs), and tissue inhibitors of metalloproteinases (TIMPs), have been implicated in cell turnover, development, migration, and metastatic processes. We used Western blot and immunohistochemistry to determine whether MMP-2 and associated proteins TIMP-2 and membrane type 1 matrix metalloproteinase (MT1-MMP) are present in the olfactory epithelium of mice. We found MMP-2 expression localized to the olfactory basal cells and immature neurons. After injury-induced neural degeneration, MMP-2 and MT1-MMP levels decreased while TIMP-2 levels increased. However, following 35 days of neurogenesis and cell replacement TIMP-2 and MT1MMP returned to control levels. The results show a correlation between MMP and TIMP levels and the stages of neural degeneration, regeneration and recovery of the olfactory epithelium following injury.
\end{abstract}

\section{Keywords}

Matrix metalloproteinase; Mouse; Nerve outgrowth; Olfactory epithelium; Progenitor cell; Regeneration

\section{INTRODUCTION}

The olfactory epithelium is a region of continuous neurogenesis, cell proliferation, migration and differentiation. It provides a unique model for the study of molecules involved in the turnover of neural progenitor cells and remodeling of the extracellular environment during neurite outgrowth [1-3].

The olfactory epithelium consists of three major cell types: olfactory receptor neurons, supporting cells and basal cells [4]. The basal cell layer of the olfactory epithelium contains neuronal progenitor cells that continuously generate new receptor neurons [2]. Olfactory

(C) 2003 Lippincott Williams \& Wilkins

CACorresponding Author: E-mail: rcostanz@mail2.vcu.edu. 
receptor cells are bipolar neurons derived from the differentiation of basal cells. Their axons penetrate the basement membrane of the epithelium where they form unmyelinated axon bundles surrounded by olfactory ensheathing cells. The continuous replacement of olfactory neurons by basal cells occurs throughout the life span of vertebrates, and in response to neuronal injury [5]. Following injury there is a rapid degeneration of olfactory neurons and an increase in basal cell proliferation. Once basal cells receive the signal to proliferate, migrate to a new position, and differentiate into new olfactory receptor cells, they must send out both dendrite and axon processes to reach the epithelial surface and olfactory bulb. The differentiation and replacement of olfactory neurons involves communication between neighboring cells and the reorganization of the extracellular milieu [6]. Understanding the molecules responsible for the regulation of neurogenesis, migration and maturation of olfactory neurons, as well as molecules that guide olfactory axon fibers to specific target areas in the olfactory bulb may provide insight into the restorative capacities of the nervous system.

Matrix metalloproteinases (MMPs) are mediators of extracellular remodeling that occurs in developmental, reparative, homeostatic and metastatic processes [7,8]. MMPs can degrade extracellular matrix molecules, cell surface molecules, and modulate the bioavailability of growth factors. Growth factors and cell surface cytokines in turn regulate other processes such as cell proliferation and cell recruitment. Members of the MMP family of molecules have also been found in the nervous system [9-11], and have been implicated in both normal and pathological processes [12]. MMP-2, a type IV collagenase, is associated with the degradation of extracellular matrix molecules. MMP-2 activity can be modulated by tissue inhibitors of metalloproteinases-2 (TIMP-2), and membrane type 1 matrix metalloproteinase (MT1-MMP), which initiates the activation of MMP-2 [7,13].

In the present study we demonstrate for the first time the presence of MMP-2, MT1-MMP and TIMP-2 in the olfactory epithelium, a well-characterized model of neuronal degeneration and recovery $[14,15]$.

\section{MATERIALS AND METHODS}

\section{Surgical procedures}

Adult CD-1 mice (Charles River Lakeview, Wilmington, MA, USA) were anesthetized with sodium pentobarbital ( $80 \mathrm{mg} / \mathrm{kg}$, i.p.). After anesthesia, removal of bulb tissue (bulbectomy) was achieved by aspiration using a sterile 23 gauge needle. This assured the transection of olfactory nerve fibers that project into the bulb. All procedures were approved by the Institutional Animal Care and Use Committee of Virginia Commonwealth University.

\section{Western blot analysis}

At $1,4,7,11,15$ or 35 days after bilateral bulbectomy, animals were deeply anesthetized with carbon dioxide, sacrificed by rapid decapitation and tissue samples removed from the nasal cavity. Tissue samples from control animals were also obtained using the same procedure. Strips of olfactory epithelium were collected from the nasal septum and dorsal recess areas of the right and left sides of the nasal cavity. Epithelium samples were not obtained from the turbinate areas due to contamination with bone and cartilage, which are known to have high levels of MMPs. Immediately following removal of the olfactory epithelium the tissue was immersed in protein extraction buffer $(50 \mathrm{mM}$ Tris- $\mathrm{HCl}, 150 \mathrm{mM} \mathrm{NaCl}, 1 \% \mathrm{NP}-40,1 \%$ sodium deoxycholate, $1 \%$ sodium dodecyl sulfate) containing a protein inhibitor cocktail (Calbiochem, San Diego, California, USA) and homogenized. The tissue was incubated at $4^{\circ} \mathrm{C}$ for $15 \mathrm{~min}$ and then centrifuged at 16000 r.p.m. for $15 \mathrm{~min}$ at $4^{\circ} \mathrm{C}$. Solubilized proteins in the supernatant were then assayed. Extracted protein was quantified against a bovine serum albumin (BSA) standard using a DC protein assay reagent kit (Bio-Rad, Hercules, California). Measurements 
were made at 720nm using a BMG Fluorostar Galaxy 403 plate reader (BMG Lab Technologies, Inc. Offenburg, Germany). Equal protein was loaded onto Bis-Tris 4-12\% density gradient gels and electrophoresis was performed using NuPAGE MES [12(Nmorpholino) ethane sulfonic acid] reducing buffer system (Invitrogen, Carlsbad, California, USA) for $50 \mathrm{~min}$ at $200 \mathrm{~V}$. Protein was transferred to nitrocellulose membranes for $2 \mathrm{~h}$ at $25 \mathrm{~V}$. Non-specific binding was blocked with $5 \%$ bovine milk in TBS-T (Tris buffered saline plus 0.05\% Tween 20). Primary antibodies against MMP-2 (AB809, 1:1000), MT1-MMP (1:2000) and TIMP-2 (1:500) were obtained from Chemicon International, Temecula, California, USA. Anti-GAP-43 antibody (Novus Biochemicals, Littleton, CO, USA; 1:4,000) and anti-olfactory marker protein antibody (gift of Dr Frank Margolis, 1:40,000), were used to assay degeneration and regeneration of the olfactory receptor neurons. Anti-cyclophyllin A antibody (Upstate, Lake Placid, NY, USA; 1:2000) was used as a standard to determine protein loading. All densitometer measurements were adjusted for protein loading using cyclophyllin A. For MMP-2, TIMP-2, GAP-43 and cyclophyllin A, the nitrocellulose membranes were treated with species-specific peroxidase conjugated IgG (Rockland, Gilbertsville, PA, USA) and exposed to Blue Sensitive Autoradiography Film (Marsh Bioproducts, Rochester, NY, USA) after a 1 min incubation with ECL detection reagents (Amersham Pharmacia Biotech, Piscataway, NJ, USA). For MT1-MMP and OMP, membranes were treated with species-specific biotinylated secondary antibodies (Jackson Immuno Research Laboratories, West Grove, PA, USA) and an avidin-biotinylated horseradish peroxidase system (Vector Laboratories, Burlingame, CA, USA).

\section{Immunohistochemistry}

For immunohistology, experimental animals $(n=15)$ received a unilateral bulbectomy (removal of the left olfactory bulb) and histological sections were prepared from animals after 4, 7, 11, 15 and 35 days. Control animals $(n=3)$ did not receive the bulbectomy procedure and sections from these animals served as reference tissue. After deep anesthesia with pentobarbital ( $90 \mathrm{mg} /$ $\mathrm{kg}$ ), mice were perfused intracardially using $4 \%$ paraformaldehyde in phosphate buffer proceeded by a phosphate-buffered saline (PBS) rinse. The nasal cavity and anterior portion of the skull were removed en block and postfixed by immersion in $4 \%$ paraformaldehyde for $1 \mathrm{~h}$ and then placed in a decalcification solution for 5-7 days. The tissue was cryoprotected with $30 \%$ sucrose for 2 days, then immersed in embedding compound, snap-frozen in liquid nitrogen and sectioned on a cryostat. Serial coronal sections were cut at $7.5 \mu \mathrm{m}$ and mounted on glass slides. Sections were then processed by immersion for 1 min intervals in a series of alcohol solutions (70, 95, 100, 95, 70\% ethanol) and incubated with $0.5 \%$ BSA, $0.3 \%$ Triton X-100 in Tris-buffered saline for $30 \mathrm{~min}$. Sections were treated with $0.03 \% \mathrm{H}_{2} \mathrm{O}_{2}$ for $10 \mathrm{~min}$ to block endogenous peroxidase activity and then DAKO protein block serum-free (DAKO, Carpinteria, CA, USA) for 10 min to block non-specific binding. Sections were then reacted overnight at $4{ }^{\circ} \mathrm{C}$ with one of the following primary antibodies: anti-MMP-2 polyclonal antibody (Catalog AB808, Chemicon International; 1:1000), anti-olfactory marker protein antibody (gift of Dr Frank Margolis, 1:20,000) or anti-GAP-43 antibody (Novus Biologicals; 1:4000). Antibodies were visualized using goat anti-rabbit immunoglobulins conjugated to a peroxidase-labeled polymer (DAKO EnVision $+{ }^{\mathrm{TM}}$, DAKO) or biotinylated rabbit anti-goat immunoglobulins (Jackson ImmunoResearch laboratories) and avidin-biotinylated horseradish peroxidase system (Vector Laboratories). Diaminobenzidine (DAB) was used as a chromogen. Negative controls consisted of replacing the primary antibody with the immunoglobulin fraction of serum from non-immunized rabbits (DAKO, X0903) at a concentration level identical to the primary antibody. 


\section{RESULTS}

\section{MMP-2 expression in the olfactory epithelium}

We used Western blot analysis to study protein expression at different time points during degeneration, neurogenesis, and replacement of olfactory receptor neurons following bilateral bulbectomy. Western immunoblot data for proteins expressed in the olfactory epithelium are shown in Fig. 1. Densitometric measurements of protein bands (Fig. 1a,b) were normalized to cyclophyllin A and plotted in Fig. 1c,d.

MMP-2, MT1-MMP and TIMP-2 were present in all samples of the olfactory epithelium, including those from control animals. Following bulbectomy, MMP-2 levels decreased reaching a low point at day 11 (Fig. 1c). A slight increase in MMP-2 was observed at day 15, and higher levels were obtained on day 35. MT1-MMP expression also decreased following bulbectomy. However, there was a large decrease in MT1-MMP only 1 day after bulbectomy, and levels continued to decrease until day 11. Recovery of MT1-MMP was first observed on day 15 and a return to control levels was observed on day 35. In contrast to MMP-2 and MT1MMP, TIMP-2 levels were relatively low in control animals and increased after bulbectomy. TIMP-2 levels peaked at day 11, which is the opposite of MMP-2. TIMP-2 returned to control levels by day 35 .

The time course of neural degeneration in the olfactory epithelium following bulbectomy, and the subsequent neurogenesis and replacement with new cells, were monitored using antibodies to the olfactory marker protein, which recognizes mature olfactory receptor cells, and the growth associated protein (GAP-43), a marker for immature developing neurons. The expression of the olfactory marker protein decreased beginning at day 4 , indicating a degeneration of the mature olfactory neurons. Expression remained low until day 11 and showed a gradual increase beginning at day 15 (Fig. 1d). GAP-43 showed increased levels of expression beginning at day 7 , indicating a replacement with immature neurons. Maximum expression of GAP-43 was observed at day 15 and it returned to control levels by day 35 . These data are consistent with the time course of degeneration and recovery of olfactory receptor neurons reported in the hamster, rat and mouse [14-16]. These results demonstrate for the first time that changes in MMP-2, MT1-MMP and TIMP-2 expression are associated with phases of olfactory cell neurogenesis, growth and development of immature neurons.

\section{MMP-2 is localized to the basal cell layer}

Immunohistochemical sections of the olfactory epithelium from control animals revealed a localization of MMP-2 staining to the basal and immature cell layers near the basement membrane (Fig. 2, arrowheads). Staining was not observed in negative control sections (not shown). Immature olfactory cells, their dendrites and axons were identified using GAP-43 staining. GAP-43 did not stain basal cells located near the basement membrane (Fig. 2, asterisks). Olfactory marker protein staining was used to identify the mature receptor neurons located in the upper layers of the epithelium. At days 4 and 7 following bulbectomy, there was a marked degeneration of the mature receptor neurons and a decrease in the thickness of the epithelium. At day 7, only a few MMP-2-positive cells were observed in the basal cell layer (Fig. 2, Day 7, arrowhead) and the thickness of the epithelium had reached its lowest level. Consistent with the olfactory degeneration-regeneration model, the mature neurons, positive for the olfactory marker protein, degenerate after their axons are removed by bulbectomy. However, GAP-43-positive immature cells are spared from bulbectomy because their axons had not reached the olfactory bulb. At days 11 and 15 there was an increase in the number of cells and the thickness. At day 15, there was an increase in MMP-2 expression in the basal and immature cell layers (Fig. 2, day 15, arrowheads), and just below the basement membrane, the outgrowth of MMP-2-positive axon processes can be seen (Fig. 2, day 15, arrows). The increase 
in GAP-43- and olfactory marker-protein-positive cells seen at day 15 indicates the remarkable capacity of the olfactory epithelium to undergo neurogenesis and replacement of its olfactory neurons. At day 35 there was a further increase in MMP-2 expression in the basal cell layer. In addition, GAP-43 staining decreased while olfactory marker protein staining increased. These results demonstrate the localization of MMP-2 expression in the olfactory epithelium, and that the expression levels change during the degeneration and recovery of olfactory neurons following bulbectomy.

\section{MMP-2 expression is associated with axon outgrowth}

In addition to the MMP-2 staining observed among the basal cells adjacent to the basement membrane, staining was sometimes seen along the surface of axon bundles extending deep into the lamina propria in control animals (Fig. 3a,b). This could represent the labeling of olfactory ensheathing cells that surround axon bundles. After recovery from olfactory bulbectomy (Fig. $3 \mathrm{c}, \mathrm{d}$ ), MMP-2 staining was observed on axon processes (arrows) associated with newly differentiated neurons (arrowhead). We also observed MMP-2 staining in the deep layers of the lamina propria during recovery days 7, 11 and 15 . These data provide evidence that MMP-2 activity may be associated with the outgrowth of axons and the ensheathing cells that surround olfactory nerve bundles.

\section{DISCUSSION}

The primary function of MMPs is thought to be the degradation and remodeling of the extracellular matrix. Recently, MMPs have been implicated in many processes, including morphogenesis, cell migration, proliferation, apoptosis and wound healing. We hypothesized that MMPs might be present in the olfactory epithelium because in this system there is a continuous neurogenesis in the basal cell layer resulting in the differentiation, migration and replacement of mature olfactory receptor cells. Our results are the first to report the expression of MMP-2 in the olfactory epithelium.

We found that MMP-2, MT1-MMP and TIMP-2 are temporally expressed (Fig. 1) during olfactory degeneration, neurogenesis and axonal outgrowth following injury. In the normal olfactory epithelium, MMP-2 was localized to cells in the basal cell layer as well as axon outgrowth processes extending into the lamina propria (Fig. 2 and Fig 3). These findings suggest that MMP-2 activity may be associated with axon elongation and cell turnover within the basal cell layer.

MMP-2 can be activated by interactions with MT1-MMP and TIMP-2 at the cell surface [17]. TIMPs reversibly inhibit MMPs in a 1:1 stoichiometric manner [18]. We observed that when TIMP-2 levels are at their peak, MMP-2 levels are at their lowest point, suggesting inhibition of MMP-2 activation (Fig. 1). Independent of the inhibitory activity of TIMPs towards MMPs, TIMPs also act as mitogens [7] and have been shown to be spatially and temporally regulated in the developing CNS [19]. Interestingly, in this study the highest expression of TIMP-2 was seen during the regenerative and proliferative phases of cell replacement.

Both molecular processes and specific proteins have been implicated in the remodeling of the microenvironment that permits the successful connection of axons to specific targets in the nervous system. Laminin promotes neurite outgrowth in in vitro bioassays of regenerating dorsal root ganglionic neurons, and chrondroitin sulfate proteoglycans upregulated after peripheral nerve injury inhibit this activity. MMP-2 has been shown to reverse the inhibition of laminin by proteolysis of chrondroitin sulfate proteoglycan in this model [20]. In the olfactory system, laminin has also been shown to stimulate migration of neuronal precursors and promote neurite outgrowth along olfactory ensheathing cells. Chondroitin sulfate 
proteoglycans in the surrounding mesenchyme inhibit cell spreading and confine the neurite outgrowth to specific pathways [6]. Our finding that MMP-2 is present during normal maintenance of the olfactory epithelium suggests a possible role in the regulation of olfactory neuron outgrowth. The slow recovery of both OMP and MMP-2 levels after injury may be related to the death of mature olfactory neurons and the disruption of cell to cell interactions within the epithelium.

\section{CONCLUSION}

The presence of MMP-2, TIMP-2, and MT1-MMP in the olfactory epithelium suggests that MMPs may play a role in the normal maintenance of the epithelium. The localization of MMP-2 staining and the temporal expression of the three proteins during olfactory degeneration and regeneration further suggest that MMPs are involved in mechanisms of neural recovery. Future investigations using the olfactory epithelium as a research model may provide a better understanding of the role of MMPs and TIMPs in neurogenesis, migration, and outgrowth of neurons.

\section{Acknowledgment}

We thank Dr Frank Margolis for his generous gift of the olfactory marker protein antiserum. This work was supported by Public Health Service grantDC-00165 from the National Institute of Deafness and Other Communication Disorders.

\section{References}

1. Costanzo RM. Ciba Found Symp 1991;160:233-242. [PubMed: 1752165]

2. Calof AL, Mumm JS, Rim PC, et al. J Neurobiol 1998;36:190-205. [PubMed: 9712304]

3. Graziadei PPC, Monti Graziadei GA. Am J Otolaryngol 1983;4:228-233. [PubMed: 6353965]

4. Holbrook EH, Szumowski KE, Schwob JE. J Comp Neurol 1995;363:129-146. [PubMed: 8682932]

5. Schwob JE. Anat Rec 2002;269:33-49. [PubMed: 11891623]

6. Tisay KT, Key B. J Neurosci 1999;19:9890-9899. [PubMed: 10559398]

7. Sternlicht MD, Werb Z. Annu Rev Cell Dev Biol 2001;17:463-516. [PubMed: 11687497]

8. Vu TH, Werb Z. Genes Dev 2000;14:2123-2133. [PubMed: 10970876]

9. Vaillant C, Didier-Bazes M, Hutter A, et al. J Neurosci 1999;19:4994-5004. [PubMed: 10366632]

10. Muir D. Exp Cell Res 1994;210:243-252. [PubMed: 8299723]

11. Frolichsthal-Schoeller P, Vescovi AL, Krekoski CA, et al. Neuroreport 1999;10:345-351. [PubMed: 10203333]

12. Pagenstecher A, Stalder AK, Kincaid CL, et al. Am J Pathol 1998;152:729-741. [PubMed: 9502415]

13. Sato H, Takino T, Okada Y, et al. Nature 1994;370:61-65. [PubMed: 8015608]

14. Schwob JE, Youngentob SL, Mezza RC. J Comp Neurol 1995;359:15-37. [PubMed: 8557844]

15. Costanzo RM, Graziadei PP. J Comp Neurol 1983;215:370-381. [PubMed: 6863590]

16. Matulionis DH. Am J Anat 1976;145:79-99. [PubMed: 1246968]

17. Strongin AY, Collier I, Bannikov G, et al. J Biol Chem 1995;270:5331-5338. [PubMed: 7890645]

18. Edwards, DR. The tissue inhibitors of metalloproteinases. In: Clendeninn, NJ.; Appelt, K., editors. Matrix Metalloproteinase Inhibitors in Cancer Therapy. Humana Press; 2000. p. 67-84.

19. Fager N, Jaworski DM. Mech Dev 2000;98:105-109. [PubMed: 11044612]

20. Zuo J, Ferguson TA, Hernandez YJ, et al. J Neurosci 1998;18:5203-5211. [PubMed: 9651203] 


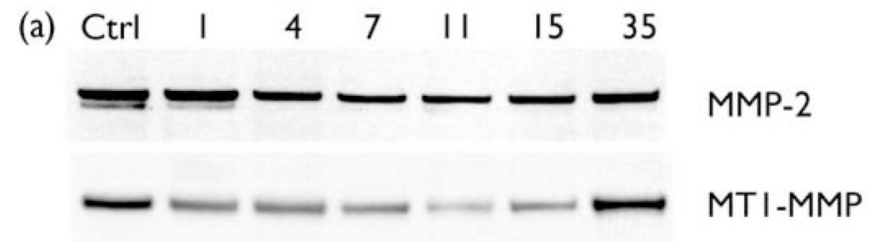

TIMP-2
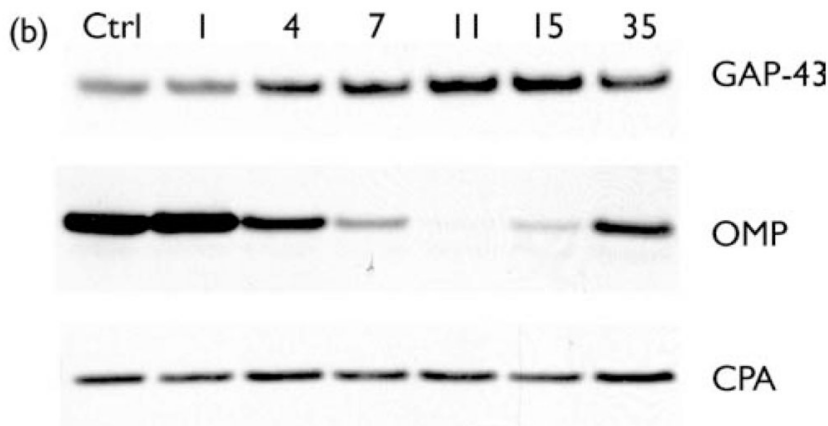

CPA

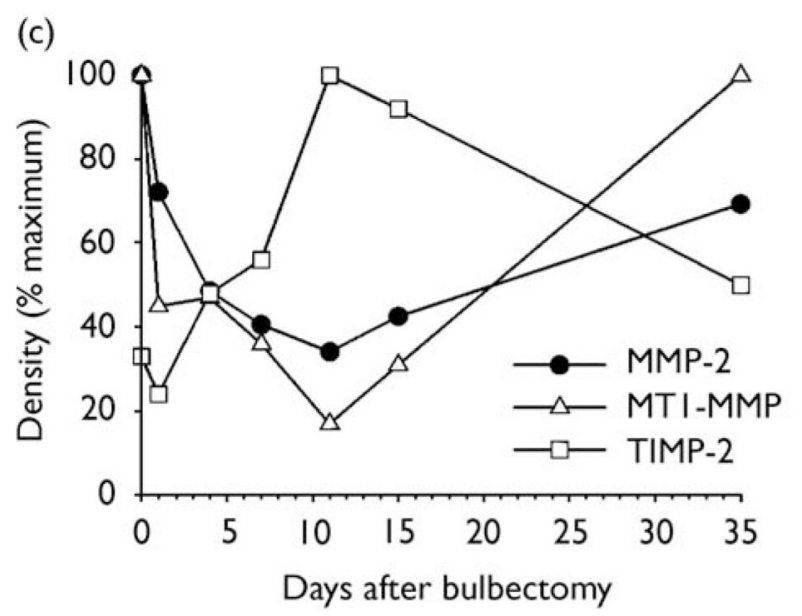

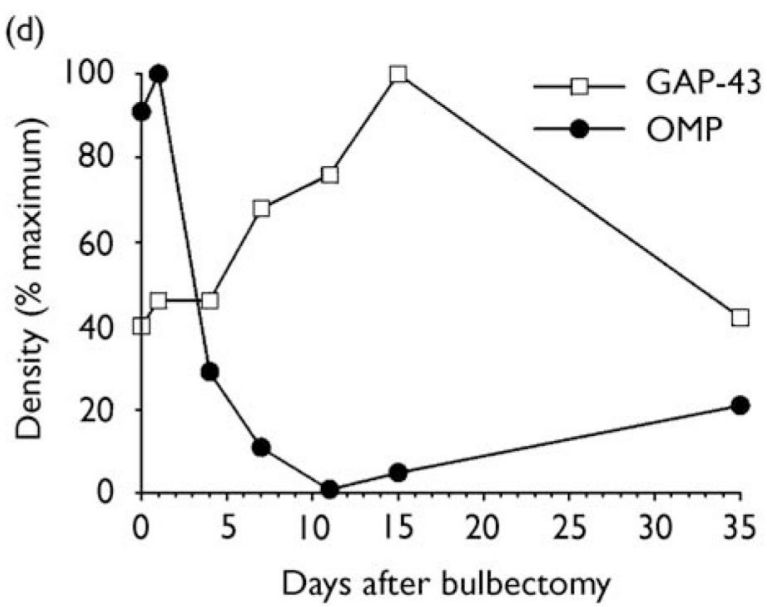

Fig.1.

Western immunoblot analysis of protein expression in the olfactory epithelium. (a,b)

Representative Western blot showing protein expression in control tissue (Ctrl), and changes during degeneration and recovery following bulbectomy. Both the pro form (heavy band) and active form (lighter band) of MMP-2 can be seen in control tissue. Growth-associated protein (GAP-43) and olfactory marker protein (OMP) were used to monitor changes in immature and mature olfactory neurons. (c,d) Plot of densitometric measurements for each protein shown in (a,b) normalization to cyclophyllin A (CPA) and expressed as a percentage of the maximum value. (c) Immediately following bulbectomy MMP-2 and MT1-MMP levels decreasedwhileTIMP-2 levels increased. Beginning at day 11, a gradual recovery in MMP-2 and MT1-MMP was observed and TIMP-2 began to decline. (d) During the first 7 days after bulbectomy, degeneration of the mature olfactory neurons was detected by a decrease in OMP. The increase inGAP-43 levels beginning at day 4 and peaking at day 15 indicates growth of the immature replacement neurons. 


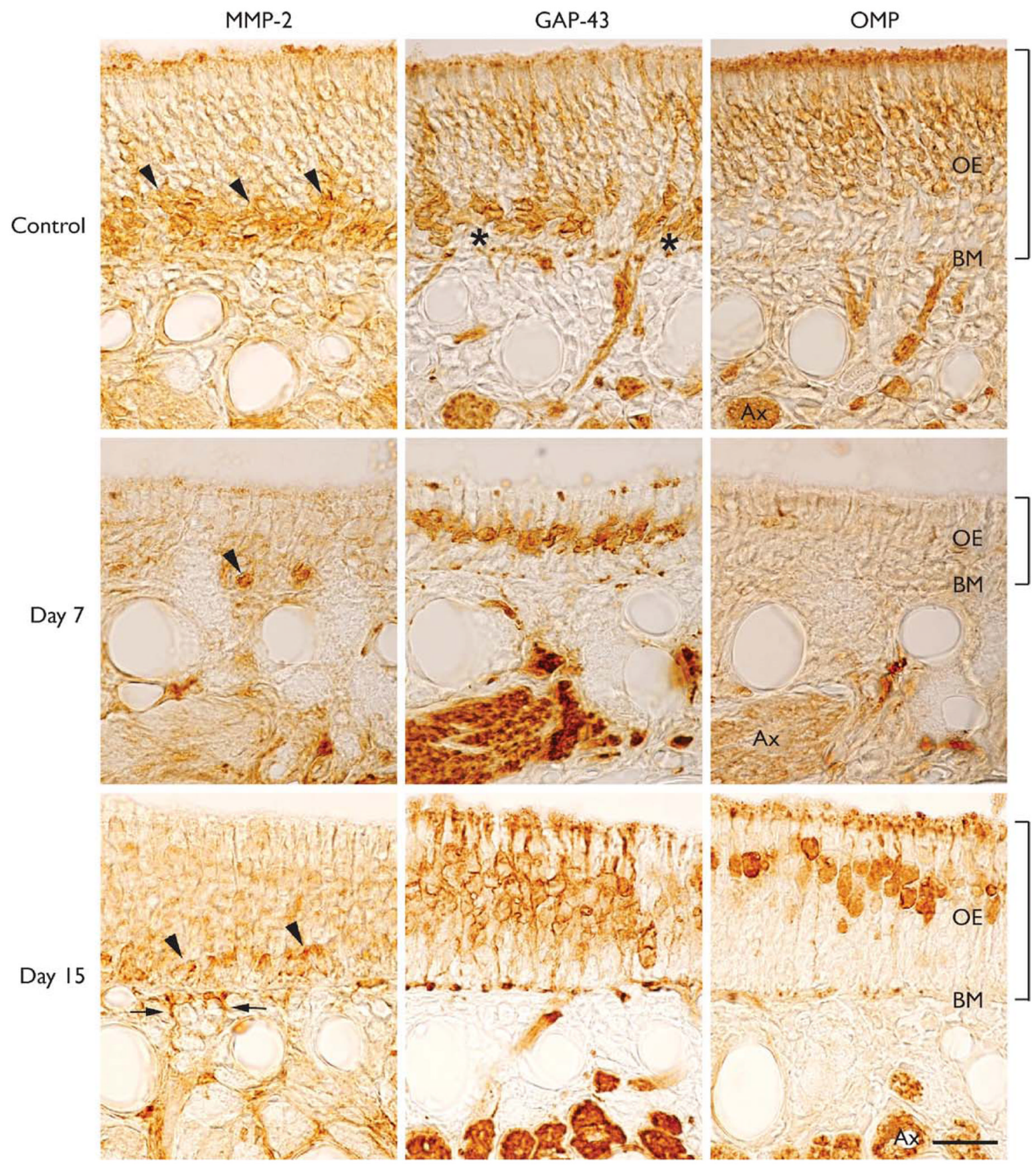

Fig.2.

Expression and localization of MMP-2, GAP-43 and OMP in the olfactory epithelium of control and bulbectomizedmice. (Control) MMP-2 expression is seen among the basal cells and immature olfactory neurons (arrowheads). Basal cells (asterisks) located adjacent to the basement membrane (BM) did not stain with anti GAP-43 antibodies. Only the immature neurons, their dendrites and axon bundles were GAP-43-positive. OMP identified the population of mature olfactory neurons. (Day 7) After bulbectomy the thickness of the olfactory epithelium (OE) decreased and very few MMP-2 positive cells were observed (arrowhead). At this time point there were many GAP-43-positive cells and only an occasional OMP-positive neuron (Day 15).An increase in the number of MMP-2-positive cells was observed in the basal 
and immature cell layers (arrowheads) of the epithelium, and just below the basement membrane newly growing axons were observed (arrows).GAP-43-positive cells were present above the layer of MMP-2-positive cells and more OMP-positive cells were present in the epithelium. Tissue sections for each time point shown are near adjacent sections from the nasal septum. Brackets indicate thickness of the epithelium. Bar $=25 \mu \mathrm{m}$. 

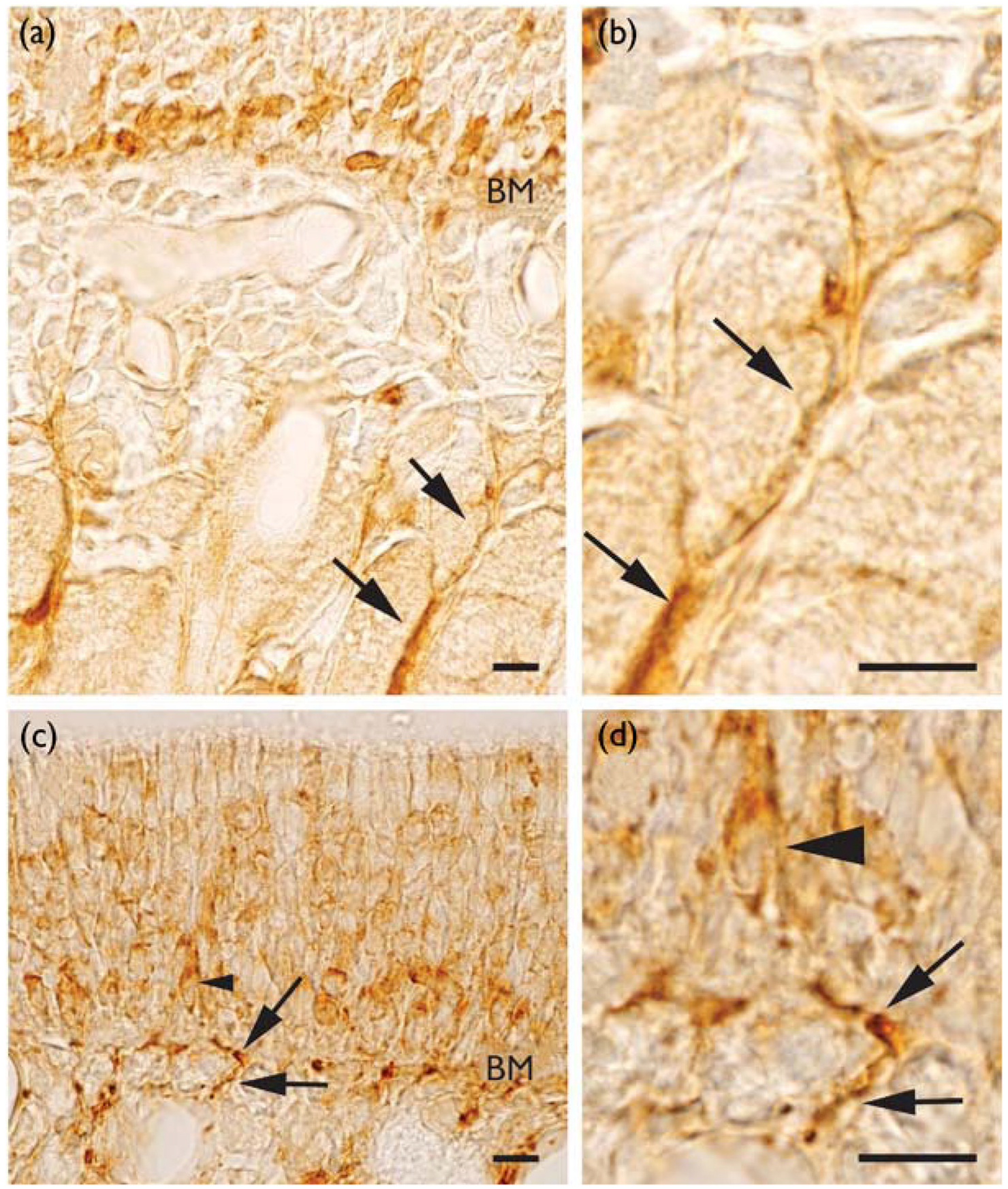

Fig.3.

MMP-2 expression associated with axon outgrowth. (a,b) In control animals, MMP-2 expression was observed among basal cells and in the lamina propria (arrows). (b) High magnification of lamina propria shown in (a). (c,d) After recovery from bulbectomy (day 15), MMP-2 expression is observed among the basal cells and axon processes. A young developing neuron (arrowhead) and its axon process (arrows) can be seen passing through the basement membrane (BM). (d) Higher magnification of axon process shown in (c). Bar $=10 \mu \mathrm{m}$. 